\title{
Evaluation of biometry and corneal astigmatism in cataract surgery patients from Central China
}

\author{
Ji-guo Yu ${ }^{\dagger}$, Jie Zhong ${ }^{\dagger}$, Zhong-ming Mei, Fang Zhao, Na Tao and Yi Xiang ${ }^{*}$
}

\begin{abstract}
Background: To evaluate the distribution of biometric parameters and corneal astigmatism using the IOLMaster device before phacoemulsification in cataract patients in Central China.

Methods: Consecutive cataract patients were recruited at the Central Hospital of Wuhan between January 2015 and June 2016. Ocular axial length (AL), keratometry values, anterior chamber depth (ACD) and horizontal corneal diameter (white to white [WTW]) of each cataract-affected eye were measured with the IOLMaster device.

Results: The study evaluated 3209 eyes of 2821 cataract patients. The mean AL, ACD, and WTW were $24.38 \pm 2.47 \mathrm{~mm}, 3$. $15 \pm 0.48 \mathrm{~mm}$, and $11.63 \pm 0.43 \mathrm{~mm}$, respectively. Corneal astigmatism of $0.51-1.00$ diopters (D) was the most common range of values (34.96\%). A total of $10.56 \%$ patients exhibited a corneal astigmatism greater than $2.0 \mathrm{D}$. The flat and steep keratometry values gradually increased with age. The mean ACD and WTW showed increasing trends as the AL increased $(P<0.001)$. When the AL was shorter than $26.0 \mathrm{~mm}$, the keratometry decreased as AL increased. The against-the-rule (ATR) astigmatism proportion increased with age and the with-the-rule (WTR) astigmatism proportion decreased with age.
\end{abstract}

Conclusions: The profile of ocular biometric data and corneal astigmatism may help ophthalmologists improve their surgical procedures and make an appropriate IOL choice to gain a high quality of postoperative vision.

Keywords: Biometry, Corneal astigmatism, Cataract, IOLMaster device, Central China

\section{Background}

Cataract is the leading cause of blindness and the only form of treatment is surgery. Phacoemulsification is the most commonly used and effective surgical method for the treatment of cataract worldwide. Accurate measurement of ocular axial length, keratometry, anterior chamber depth and corneal diameter before cataract surgery is crucial for obtaining the precise degree of implanted intraocular lens (IOL) to control the postoperative diopter (D) value plus or minus $0.50 \mathrm{D}$ as well as to achieve satisfactory postoperative refractive results and improve the visual quality for cataract patients $[1,2]$.

Partial coherence interferometry (IOLMaster, Carl Zeiss Meditec, Germany) is a type of optical coherent biological measuring instrument that utilizes non-contact

\footnotetext{
* Correspondence: xyyanke@163.com

${ }^{\dagger}$ Equal contributors

Department of Ophthalmology, the Central Hospital of Wuhan, Tongji Medical College, Huazhong University of Science and Technology, No, 26 Shengli Street, Wuhan, Hubei Province 430014, China
}

technology to measure axial length, keratometry, anterior chamber depth and corneal diameter. With its ultra-high precision (5 $\mathrm{mm}$ or less) and good resolution $(12 \mathrm{~mm})$, it is widely used in evaluating the ocular parameters and IOL calculations in cataract patients before surgery. Through its innovative and accurate measurement of ocular parameters, the degree of intraocular lens can be accurately calculated before implantation [3]. Corneal astigmatism is also a major factor affecting postoperative visual quality. The IOLMaster can measure preoperative corneal astigmatism and predict the residual corneal astigmatism after cataract surgery [4].

However, most previous studies of preoperative ocular biometry and corneal astigmatism on cataract patients focused on the European and American populations [5-8]. Although there have been some domestic related studies, they aimed to evaluate the Southern, Northern, and Eastern Chinese populations $[1,9,10]$. However, the epidemiological investigation of ocular biometry and 
corneal astigmatism of cataract patients in the Central China region has yet to be investigated. Therefore, the aim of our study was to evaluate the distribution of biometric parameters, and determine the prevalence of corneal astigmatism using the IOLMaster measurement device before phacoemulsification in cataract patients in Central China, to provide some reference for improving cataract surgical procedures and designing an intraocular lens to meet eye characteristics of the Central Chinese population.

\section{Methods}

\section{Subjects}

This study was approved by the institutional ethics committee of the Central Hospital of Wuhan (Hubei, Central China), and followed the tenets of the Declaration of Helsinki. Consecutive cataract patients scheduled for phacoemulsification and foldable IOL implantation were recruited at the Central Hospital of Wuhan between January 2015 and June 2016. All patients who were local residents of Central China, had cataract, and were older than 30 years were included. Exclusion criteria included a history of ocular surgery, such as refractive surgery, corneal diseases, ocular inflammation, and trauma; patients from other areas of China were also excluded. Routine eye examinations were performed before surgery, including visual acuity, refraction, tonometry, slit lamp evaluation, and dilated fundus evaluation. The procedures were fully explained to each patient, and they provided written informed consent.

\section{Biometry examination}

Ocular axial length (AL), keratometry values, anterior chamber depth (ACD) and horizontal corneal diameter (white to white [WTW]) of each cataract-affected eye were measured with the IOLMaster (Carl Zeiss Meditec, Germany, software version 5.4). Keratometry was measured in 2 meridians: that is, flat keratometry (K1) and steep keratometry (K2). The $\mathrm{K}$ value was calculated as the mean of $\mathrm{K} 1$ and $\mathrm{K} 2$. The patients were divided into 7 groups on the basis of age as follows: $30-40$ years, 41-50 years, $51-60$ years, $61-70$ years, $71-80$ years, 81-90 years, and 90 years and older. All eyes were stratified into 4 groups based on $\mathrm{AL}$ as follows: shorter than $22.0 \mathrm{~mm}, 22.0-24.5 \mathrm{~mm}$, longer than $24.5 \mathrm{~mm}-$ $26.0 \mathrm{~mm}$, and longer than $26.0 \mathrm{~mm}$.

\section{Statistical analysis}

All data were recorded in Microsoft Excel spreadsheets, and analyzed using the Kolmogorov-Smirnov test for normal distribution. Continuous variables were expressed as the mean \pm standard deviation for those displaying normal distribution. One-way analysis of variance and the Kruskal-Wallis test were applied for the comparison of variance for normally and non-normally distributed data among the different age groups, respectively. Statistical analysis was performed using SPSS PASW Statistics Version 18.0 software (IBM Corporation, Armonk, NY, USA). P-values less than 0.05 were considered statistically significant.

\section{Results}

\section{Distribution of ocular biometry}

This study evaluated 3209 eyes of 2821 cataract patients. The patient demographics are shown in Table 1, which also shows a comparison of these demographics with 4 other published papers that studied populations from the different regions in China. The histograms of the frequency distribution of corneal astigmatism for all patients are shown in Fig. 1. Corneal astigmatism of 0.51$1.00 \mathrm{D}$ was the most common range of values (34.96\%), followed by $1.01-1.50 \mathrm{D}$ (21.72\%), 0.0-0.50 D (21.19\%), and $1.51-2.0 \mathrm{D}(11.56 \%)$. A total of $10.56 \%$ patients exhibited a corneal astigmatism greater than $2.0 \mathrm{D}$.

\section{Different age groups}

Table 2 shows the mean and standard deviation values of all measured biometric parameter values in the 7 different age groups. The flat and steep keratometry values gradually increased with age. Most eyes in this cohort were between 71 and 80 years old (34.66\%), followed by 61 and 70 years old (33.04\%). In addition, the AL, ACD, and WTW values showed a gradually decreasing trend with age; corneal astigmatism showed first a decline and then a rising trend (Fig. 2).

\section{Distribution of axial length}

Table 3 shows the distribution of ocular biometry for different ALs. The AL in the majority of eyes was between 22.0 and $24.5 \mathrm{~mm}$ (63.63\%). The mean ACD and WTW showed increased as the AL increased $(P<0.001)$. When the $\mathrm{AL}$ was shorter than $26.0 \mathrm{~mm}$, the keratometry values (K1, K2, and K) decreased with an increase in AL. However, this trend seemed to revert in patients with an AL of more than $26.0 \mathrm{~mm}$. The smallest mean corneal astigmatism $(1.03 \mathrm{D})$ was in eyes with an AL between 22.0 and $24.5 \mathrm{~mm}$, and the largest $(1.26 \mathrm{D})$ was in eyes with a longer AL than $26.0 \mathrm{~mm}$.

\section{Distribution of corneal astigmatism}

Corneal astigmatism was with-the-rule (WTR, the steepest meridian of the cornea being within $90 \pm 30$ degrees) in 1186 eyes (36.96\%), against-the-rule (ATR, the steepest meridian of the cornea being within $180 \pm 30$ degrees) in 1535 eyes (47.83\%), and oblique (steepest meridian between 30 and 60 degrees or 120 and 150 degrees) in 488 eyes (15.21\%). The ATR astigmatism proportion increased with age and the WTR astigmatism 
Table 1 Comparison of demographic features between the present study and 4 other published studies

\begin{tabular}{|c|c|c|c|c|c|}
\hline Parameters & Present & Cui [1] & Chen [11] & Yuan [9] & Guan [10] \\
\hline Location & Central China & Southern China & Southern China & Northern China & Eastern China \\
\hline Eyes/patients & $3209 / 2821$ & $6750 / 4561$ & $4831 / 2849$ & $12,449 / 6908$ & $1430 / 827$ \\
\hline \multicolumn{6}{|l|}{ Age (y) } \\
\hline Mean \pm SD & $70.51 \pm 9.81$ & $70.4 \pm 10.5$ & $70.56 \pm 9.55$ & $69.80 \pm 11.15$ & $72.27 \pm 11.59$ \\
\hline Range & 32,95 & 40,101 & 40,95 & 30,97 & 16,98 \\
\hline Male/female & $1071 / 1750$ & $2026 / 2535$ & 1090/1759 & $3199 / 3709$ & $359 / 468$ \\
\hline \multicolumn{6}{|l|}{ Keratometry (D) } \\
\hline Mean \pm SD & $1.09 \pm 0.77$ & 0.90(Median) & $1.01 \pm 0.69$ & $1.15 \pm 0.84$ & $1.07 \pm 0.73$ \\
\hline Range & $0.0,6.21$ & NR & $0.05,6.59$ & $0.0,6.63$ & $0.06,5.52$ \\
\hline $\mathrm{K} 1$ mean $\pm \mathrm{SD}$ & $43.75 \pm 1.59$ & $43.57 \pm 1.69$ & $43.76 \pm 1.53$ & $43.93 \pm 1.67$ & $43.57 \pm 1.56$ \\
\hline $\mathrm{K} 2$ mean $\pm \mathrm{SD}$ & $44.84 \pm 1.65$ & $44.69 \pm 1.69$ & $44.76 \pm 1.56$ & $45.08 \pm 1.73$ & $44.64 \pm 1.65$ \\
\hline K mean $\pm S D$ & $44.29 \pm 1.58$ & $44.13 \pm 1.63$ & NR & $N R$ & $N R$ \\
\hline \multicolumn{6}{|c|}{ Corneal astigmatism (\%) } \\
\hline$\leq 0.5 \mathrm{D}$ & $21.19 \%$ & NR & $23.14 \%$ & $20.76 \%$ & $21.2 \%$ \\
\hline$\geq 1.0 \mathrm{D}$ & $43.85 \%$ & $43.9 \%$ & $41.3 \%$ & $47.27 \%$ & $45.46 \%$ \\
\hline$\geq 2.0 \mathrm{D}$ & $10.56 \%$ & $11.6 \%$ & $8.22 \%$ & $13.16 \%$ & $10.42 \%$ \\
\hline$\geq 3.0 \mathrm{D}$ & $2.80 \%$ & $3.4 \%$ & $1.68 \%$ & $3.75 \%$ & $2.31 \%$ \\
\hline axis & $88.82 \pm 49.63$ & NR & NR & $N R$ & $N R$ \\
\hline $\mathrm{AL}(\mathrm{mm})$ & $24.38 \pm 2.47$ & $24.07 \pm 2.14$ & $23.58 \pm 1.13$ & NR & NR \\
\hline $\mathrm{ACD}(\mathrm{mm})$ & $3.15 \pm 0.48$ & $3.01 \pm 0.57$ & $N R$ & $N R$ & $N R$ \\
\hline WTW (mm) & $11.63 \pm 0.43$ & $11.68 \pm 0.45$ & NR & NR & NR \\
\hline
\end{tabular}

$D$ diopter, $K 1$ flat keratometry, $K 2$ steep keratometry, $K$ mean keratometry, $S D$ standard deviation, $A L$ axial length, $A C D$ anterior chamber depth, $W T W$ white to white, NR not reported

proportion decreased with age. The proportion of oblique astigmatism changed little with increasing age. The percentages of WTR, ATR, and oblique corneal astigmatisms in the 7 groups are shown in Fig. 3.

\section{Discussion}

This study evaluated the distribution of ocular biometric parameters and characteristics of corneal astigmatism measured using the IOLMaster device in cataract patients residing in Central China. Studies of corneal

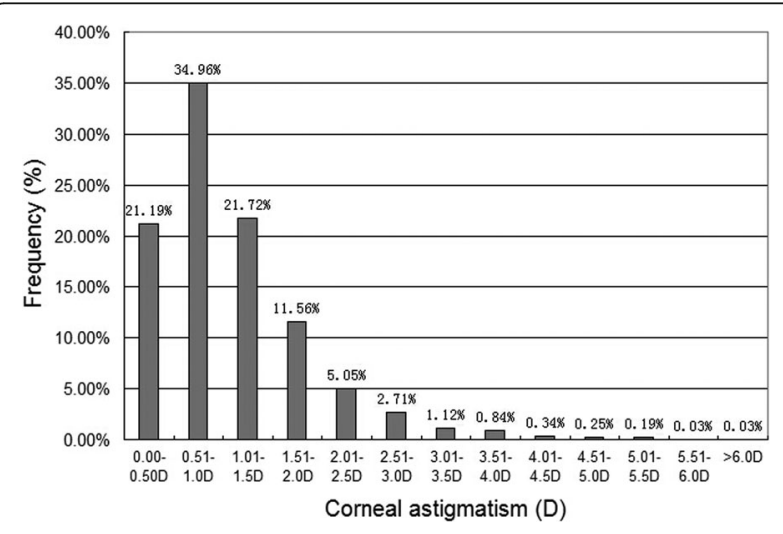

Fig. 1 Distribution of corneal astigmatism astigmatism in cataract patients from Southern $[1,11]$, Northern [9] and Eastern [10] China have previously been published. We compared these previous results with those in the present study and found that the corneal power in patients from Northern China was greater than that in other different regions, while the difference among other areas was not obvious. The highest astigmatism in patients from the four areas did not exceed $7.00 \mathrm{D}$, but the percentage of cataract patients with astigmatism higher than $1.00 \mathrm{D}$ was the greatest in Northern China. This is probably attributed to a regional difference in the populations, as well as different environmental and life style factors [12].

Corneal astigmatism across all age groups showed a similar distribution pattern compared to previous studies $[6,8,9,13]$. The vast majority of eyes with cataract had a corneal astigmatism between $0.5 \mathrm{D}$ and $1.0 \mathrm{D}$. In contrast, only a small percentage of eyes with corneal astigmatism greater than $3.0 \mathrm{D}$ were observed. Understanding the distribution of astigmatism is important to help ophthalmologists choose first-line treatment that will be most effective and reduce the occurrence of postoperative astigmatism. This includes procedures such as limbal relaxing incisions [14], opposite clear corneal incisions [15], excimer laser refractive procedures [16, 17], 
Table 2 Descriptive statistics for the 7 age groups

\begin{tabular}{|c|c|c|c|c|c|c|c|c|}
\hline Age Group (Y) & $\mathrm{AL}(\mathrm{mm})$ & $\mathrm{ACD}(\mathrm{mm})$ & WTW (mm) & Astigmatism (D) & $\mathrm{K} 1(\mathrm{D})$ mean $\pm \mathrm{SD}$ & K2 (D) mean \pm SD & $\mathrm{K}(\mathrm{D})$ mean $\pm \mathrm{SD}$ & Eyes (\%) \\
\hline $30-40$ & $26.50 \pm 2.58$ & $3.57 \pm 0.22$ & $11.79 \pm 0.41$ & $1.21 \pm 0.45$ & $42.86 \pm 1.52$ & $44.07 \pm 1.74$ & $43.47 \pm 1.62$ & $13(0.41 \%)$ \\
\hline $41-50$ & $25.10 \pm 2.70$ & $3.42 \pm 0.36$ & $11.77 \pm 0.36$ & $1.08 \pm 0.71$ & $42.87 \pm 1.33$ & $43.95 \pm 1.43$ & $43.41 \pm 1.33$ & $61(1.90 \%)$ \\
\hline $51-60$ & $25.41 \pm 3.42$ & $3.36 \pm 0.44$ & $11.70 \pm 0.45$ & $1.01 \pm 0.69$ & $43.74 \pm 1.74$ & $44.75 \pm 1.76$ & $44.24 \pm 1.71$ & $422(13.15 \%)$ \\
\hline $61-70$ & $24.68 \pm 2.66$ & $3.22 \pm 0.47$ & $11.68 \pm 0.39$ & $1.01 \pm 0.72$ & $43.81 \pm 1.56$ & $44.82 \pm 1.64$ & $44.32 \pm 1.55$ & 1060(33.04\% \\
\hline $71-80$ & $23.95 \pm 1.89$ & $3.06 \pm 0.44$ & $11.57 \pm 0.44$ & $1.13 \pm 0.82$ & $43.78 \pm 1.56$ & $44.91 \pm 1.62$ & $44.35 \pm 1.53$ & $1112(34.66 \%$ \\
\hline $81-90$ & $23.74 \pm 1.69$ & $2.95 \pm 0.52$ & $11.58 \pm 0.43$ & $1.22 \pm 0.76$ & $43.68 \pm 1.60$ & $44.89 \pm 1.65$ & $44.29 \pm 1.58$ & $514(15.99 \%)$ \\
\hline$>90$ & $23.50 \pm 1.33$ & $2.70 \pm 0.27$ & $11.67 \pm 0.49$ & $1.75 \pm 1.00$ & $43.67 \pm 2.07$ & $45.42 \pm 1.93$ & $44.54 \pm 1.93$ & $27(0.85 \%)$ \\
\hline$P$-value & $<.001$ & $<.001$ & $<.001$ & $<.001$ & $<.001$ & $<.001$ & $<.001$ & \\
\hline
\end{tabular}

$Y$ years, $\mathrm{mm}$ millimeter, $D$ diopter, $K 1$ flat keratometry, $K 2$ steep keratometry, $K$ mean keratometry, $S D$ standard deviation, $A L$ axial length, $A C D$ anterior chamber depth, WTW white to white

femtosecond laser-assisted astigmatic keratotomy [18], and toric IOL implantation [19-22]. At present, toric IOL implantation is highly recognized and it can be used to correct up to $8.0 \mathrm{D}$ of corneal astigmatism after cataract surgery [23, 24]. In the present study, $21.28 \%$ of cataract patients in Central China had corneal astigmatism values between $1.5 \mathrm{D}$ and $4.0 \mathrm{D}$, most of which could be effectively corrected with toric IOLs. Therefore, the use of toric IOLs in Central China is still required, and that is not less than the demand in other parts of China.

The mean AL, ACD and WTW in the present study are consistent with that reported by Cui et al. [1], who reported on biometry characteristics of the Southern China population. Unfortunately, the data mentioned
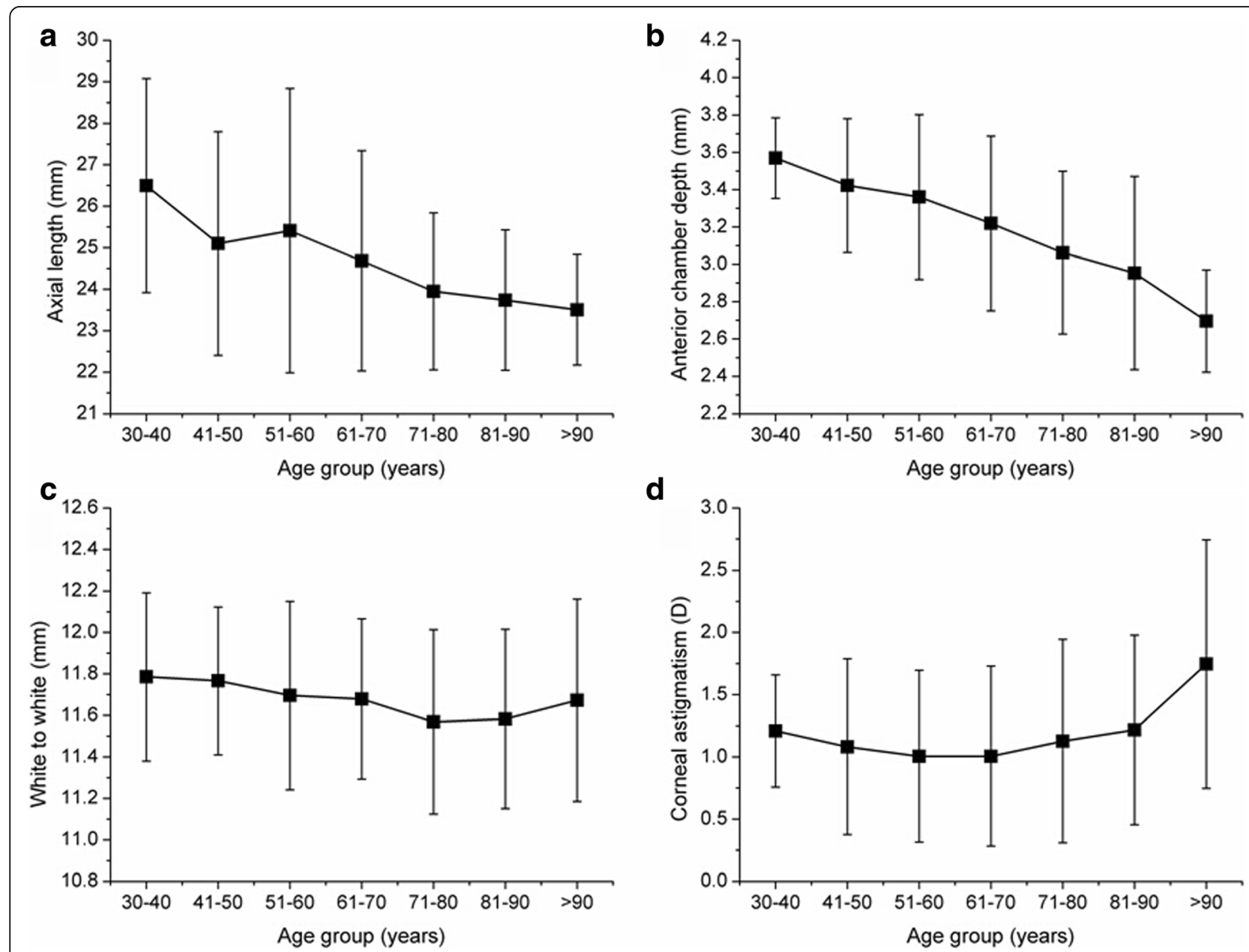

d

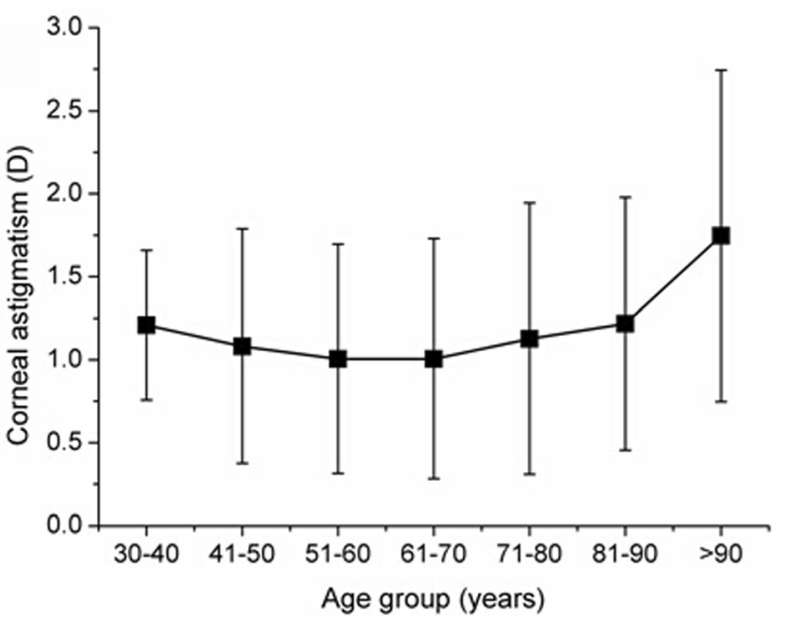

Fig. 2 The biometric parameters stratified and analyzed according to age. a Axial length, b Anterior chamber depth, $\mathbf{c}$ White to white, $\mathbf{d}$ Corneal astigmatism 
Table 3 The distribution of ocular biometry for different ALs

\begin{tabular}{|c|c|c|c|c|c|c|c|}
\hline \multirow[b]{3}{*}{$\mathrm{AL}(\mathrm{mm})$} & \multirow[b]{3}{*}{ Eyes, n (\%) } & \multicolumn{6}{|l|}{ Mean \pm SD } \\
\hline & & \multirow[b]{2}{*}{$\mathrm{ACD}(\mathrm{mm})$} & \multirow[b]{2}{*}{ WTW (mm) } & \multicolumn{3}{|c|}{ Keratometry (D) } & \multirow[b]{2}{*}{ Astigmatism (D) } \\
\hline & & & & K1 & K2 & K & \\
\hline Shorter than 22.0 & $218(6.80 \%)$ & $2.79 \pm 0.48$ & $11.38 \pm 0.46$ & $45.39 \pm 1.40$ & $46.51 \pm 1.41$ & $45.95 \pm 1.36$ & $1.12 \pm 0.75$ \\
\hline $22.0-24.5$ & $2042(63.63 \%)$ & $3.01 \pm 0.44$ & $11.62 \pm 0.42$ & $43.85 \pm 1.41$ & $44.88 \pm 1.45$ & $44.37 \pm 1.39$ & $1.03 \pm 0.72$ \\
\hline Longer than $24.5-26.0$ & $390(12.15 \%)$ & $3.35 \pm 0.37$ & $11.66 \pm 0.44$ & $43.00 \pm 1.70$ & $44.14 \pm 1.97$ & $43.57 \pm 1.79$ & $1.15 \pm 0.87$ \\
\hline Longer than 26.0 & $559(17.42 \%)$ & $3.50 \pm 0.40$ & $11.72 \pm 0.37$ & $43.32 \pm 1.71$ & $44.58 \pm 1.78$ & $43.95 \pm 1.69$ & $1.26 \pm 0.83$ \\
\hline Total & $3209(100 \%)$ & $3.15 \pm 0.48$ & $11.63 \pm 0.43$ & $43.75 \pm 1.59$ & $44.84 \pm 1.65$ & $44.29 \pm 1.58$ & $1.09 \pm 0.77$ \\
\hline$P$-value & & $<.001$ & $<.001$ & $<.001$ & $<.001$ & $<.001$ & $<.001$ \\
\hline
\end{tabular}

$\mathrm{mm}$ millimeter, $D$ diopter, $K 1$ flat keratometry, $K 2$ steep keratometry, $K$ mean keratometry, $S D$ standard deviation, $A L$ axial length, $A C D$ anterior chamber depth, WTW white to white

above were not reported for the Northern and Eastern China populations; therefore, we were unable to make a comparison with those studies. All biometric parameters that were measured using the IOLMaster device were presented as significant differences between age groups. The AL, ACD, and WTW values gradually decreased with age; corneal astigmatism showed an initial decline and then subsequently an increase. This suggests that the human eye biometric parameters change with age. This might be related to the occurrence of lens opacity and thickening, accommodative lags, cornea arcus senilis, extraocular muscle relaxation and orbital fat prolapse generating compression on the eye.

Ocular axial length affects other components of the biometric parameters in eyes. In the present study, we found that as the AL increased, ACD and WTW also increased. Additionally, the keratometry values (K1, K2, and $\mathrm{K}$ ) decreased when the AL was between 20.0 and $26.0 \mathrm{~mm}$. These results are consistent with the findings reported in previous studies $[1,6,25,26]$. This suggests that the cornea becomes flatter when the AL increases, accompanied by a larger horizontal WTW. However,

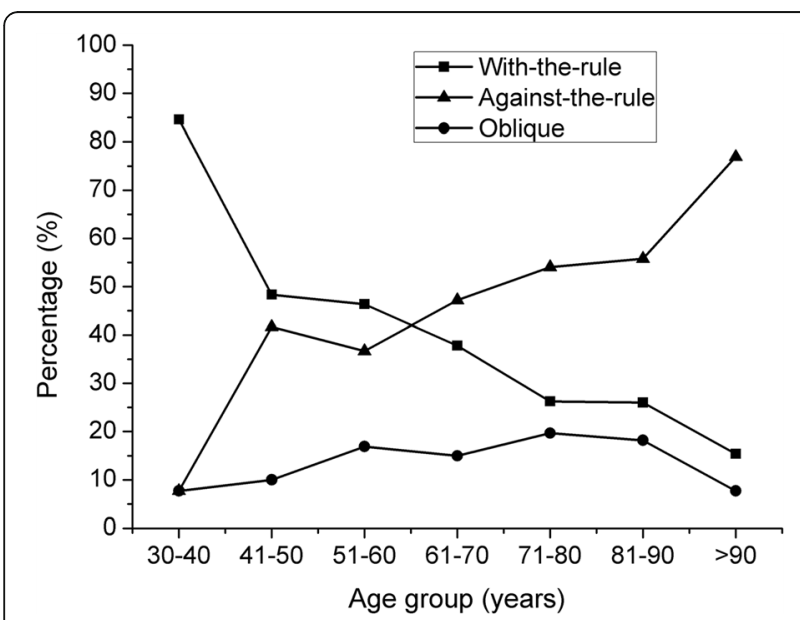

Fig. 3 Percentages of with-the-rule, against-the-rule, and oblique corneal astigmatisms in the 7 groups this characteristic was not observed when the AL was greater than $26.0 \mathrm{~mm}$. ATR astigmatism accounted for the majority of the cataract population, and the prevalence increased with age. By contrast, the percentage of WTR astigmatism decreased with age. These findings are consistent with the characteristics seen in populations from different countries and regions $[6,9,27,28]$. These changes have been found to be due to a discrepancy in eyelid morphology and power [29].

It is well known that a toric IOL is indicated when there is a corneal astigmatism of $1.50 \mathrm{D}$ or more. Although the IOLMaster measures six points of the central corneal surface within a $2.3 \mathrm{~mm}$ range, it is unable to reflect the entire corneal surface curvature. The pupil is only approximately $2.0-3.0 \mathrm{~mm}$ wide during the day, and considering the long duration of daytime eye use in most people, the IOLMaster mainly reflects the results of the central corneal astigmatism; therefore, the IOLMaster measurements also have reference values. Corneal topography can measure the total corneal astigmatism, and is more accurate for distinguishing between regular and irregular astigmatism. Therefore, we believe that for the selection of toric IOLs, one should consider both the corneal topography and IOLMaster measurements in order to make a comprehensive judgment. The current study found that a total of $710(22.13 \%)$ eyes in our study were potential candidates, however when considering implantation of toric IOLs, other factors such as the surgical techniques, economic feasibility for the patient, and rotation of the optical axis should also be taken into account. Total astigmatism is determined by corneal astigmatism, which is the major factor affecting postoperative visual quality; therefore it is crucial to select a reasonable and economical operative procedure to correct corneal astigmatism [1]. The most cost-effective methods to reduce corneal astigmatism are to make smaller incision and choose the most appropriate location for the corneal incision. Our study reported that ATR astigmatism accounted for the majority of the cataract population, and that prevalence increased 
with age. The characteristics of corneal astigmatisms in our study suggest that when considering large-scale cataract surgery for patients with a low socioeconomic status in Central China, smaller and temporal corneal incisions should be used frequently to reduce preexisting corneal astigmatism, especially in the underdeveloped areas in China.

Our study has some limitations. First, the ocular biometric data drawn from the cataract patients in our hospital do not completely represent the data of the whole population in Central China. Second, we did not make a comparative analysis of eye biometric parameters with data reported abroad because previous studies reported much more detail, and we did not compare findings between men and women. Furthermore, we did not assess the relationship between biometric parameters and genetics, diet, education, occupation, and the severity of the cataract due to lack of relevant data.

\section{Conclusions}

In conclusion, our study determined the distribution of ocular biometric parameters and the characteristics of corneal astigmatism as well as their variation among different age groups in Central China. The profile of ocular biometric data and corneal astigmatism may help ophthalmologists improve their surgical procedures including appropriate IOL choice and more accurate corneal incision made to gain a high quality of postoperative vision.

\section{Abbreviations}

ACD: Anterior chamber depth; AL: Axial length; ATR: Against-the-rule; D: Diopter; IOL: Intraocular lens; K: Mean keratometry; K1: Flat keratometry; K2: Steep keratometry; Mm: Millimeter; NR: Not reported; SD: Standard deviation; WTR: With-the-rule; WTW: White to white; Y: Years

\section{Acknowledgements}

Not applicable.

\section{Funding}

This study was supported by the Health and Family Planning Commission Fund of Wuhan, China (Grant WX16E28).

\section{Availability of data and materials}

The datasets analyzed during the current study available from the corresponding author on reasonable request.

\section{Authors' contributions}

JY and JZ contributed to research design, data collection, analysis, and interpretation as well as preparation of the manuscript. ZM and FZ contributed to data analysis and interpretation and provided major revisions to the manuscript. NT contributed to the data collection as well as the data interpretation. YX contributed to study design, study analysis and discussion, and revision of the manuscript. All authors read and approved the final manuscript.

\section{Competing interests}

The authors declare that they have no competing interests.

\section{Consent for publication}

Not applicable.

\section{Ethics approval and consent to participate}

This study was approved by the institutional ethics committee of the Central Hospital of Wuhan (Hubei, Central China), Tongji Medical College, Huazhong University of Science and Technology, and followed the tenets of the Declaration of Helsinki. Informed consent was obtained from all the individual participants included in this study.

\section{Publisher's Note}

Springer Nature remains neutral with regard to jurisdictional claims in published maps and institutional affiliations.

Received: 4 February 2017 Accepted: 22 April 2017

Published online: 26 April 2017

\section{References}

1. Cui Y, Meng Q, Guo H, Zeng J, Zhang H, Zhang G, et al. Biometry and corneal astigmatism in cataract surgery candidates from Southern China. J Cataract Refract Surg. 2014;40:1661-9.

2. Olsen T. Improved accuracy of intraocular lens power calculation with the Zeiss IOLMaster. Acta Ophthalmol Scand. 2007;85:84-7.

3. Karunaratne N. Comparison of the Pentacam equivalent keratometry reading and IOL master keratometry measurement in intraocular lens power calculations. Clin Experiment Ophthalmol. 2013;41:825-34.

4. Yong Park C, Do JR, Chuck RS. Predicting postoperative astigmatism using Scheimpflug keratometry (Pentacam) and automated keratometry (IOLMaster). Curr Eye Res. 2012;37:1091-8.

5. Fotedar R, Wang JJ, Burlutsky G, Morgan IG, Rose K, Wong TY, et al. Distribution of axial length and ocular biometry measured using partial coherence laser interferometry (IOL master) in an older white population. Ophthalmology. 2010;117:417-23.

6. Hoffmann PC, Hutz WW. Analysis of biometry and prevalence data for corneal astigmatism in 23,239 eyes. J Cataract Refract Surg. 2010;36:1479-85.

7. De Bernardo M, Zeppa L, Cennamo M, laccarino S, Rosa N. Prevalence of corneal astigmatism before cataract surgery in Caucasian patients. Eur J Ophthalmol. 2014;24:494-500.

8. Khan Ml, Muhtaseb M. Prevalence of corneal astigmatism in patients having routine cataract surgery at a teaching hospital in the United Kingdom. J Cataract Refract Surg. 2011;37:1751-5

9. Yuan X, Song H, Peng G, Hua X, Tang X. Prevalence of corneal astigmatism in patients before cataract surgery in Northern China. J Ophthalmol. 2014; 2014:536412.

10. Guan Z, Yuan F, Yuan YZ, Niu WR. Analysis of corneal astigmatism in cataract surgery candidates at a teaching hospital in shanghai. China J Cataract Refract Surg. 2012:38:1970-7.

11. Chen W, Zuo C, Chen C, Su J, Luo L, Congdon N, et al. Prevalence of corneal astigmatism before cataract surgery in Chinese patients. J Cataract Refract Surg. 2013;39:188-92

12. Meng W, Butterworth J, Malecaze F, Calvas P. Axial length of myopia: a review of current research. Ophthalmologica. 2011;225:127-34.

13. Ferrer-Blasco T, Montes-Mico R, Peixoto-de-Matos SC, Gonzalez-Meijome JM, Cervino A. Prevalence of corneal astigmatism before cataract surgery. J Cataract Refract Surg. 2009:35:70-5.

14. Ouchi M, Kinoshita S. AcrySof IQ toric IOL implantation combined with limbal relaxing incision during cataract surgery for eyes with astigmatism $>2.50 \mathrm{D}$. J Refract Surg. 2011;27:643-7.

15. Mendicute J, Irigoyen C, Ruiz M, Illarramendi I, Ferrer-Blasco T, Montes-Mico R. Toric intraocular lens versus opposite clear corneal incisions to correct astigmatism in eyes having cataract surgery. J Cataract Refract Surg. 2009;35: 451-8.

16. Gunvant P, Ablamowicz A, Gollamudi S. Predicting the necessity of LASIK enhancement after cataract surgery in patients with multifocal IOL implantation. Clin Ophthalmol. 2011:5:1281-5.

17. Norouzi H, Rahmati-Kamel M. Laser in situ keratomileusis for correction of induced astigmatism from cataract surgery. J Refract Surg. 2003;19:416-24.

18. Ruckl T, Dexl AK, Bachernegg A, Reischl V, Riha W, Ruckhofer J, et al. Femtosecond laser-assisted intrastromal arcuate keratotomy to reduce corneal astigmatism. J Cataract Refract Surg. 2013;39:528-38.

19. Horn JD. Status of toric intraocular lenses. Curr Opin Ophthalmol. 2007;18: 58-61.

20. Bachernegg A, Ruckl T, Riha W, Grabner G, Dexl AK. Rotational stability and visual outcome after implantation of a new toric intraocular lens for the 
correction of corneal astigmatism during cataract surgery. J Cataract Refract Surg. 2013;39:1390-8.

21. Bachernegg A, Ruckl T, Strohmaier C, Jell G, Grabner G, Dexl AK. Vector analysis, rotational stability, and visual outcome after implantation of a new aspheric Toric IOL. J Refract Surg. 2015;31:513-20.

22. Ferreira $T B$, Berendschot $T T$, Ribeiro FJ. Clinical outcomes after cataract surgery with a new transitional Toric intraocular lens. J Refract Surg. 2016;32:452-9.

23. Rubenstein JB, Raciti M. Approaches to corneal astigmatism in cataract surgery. Curr Opin Ophthalmol. 2013;24:30-4.

24. Kessel L, Andresen J, Tendal B, Erngaard D, Flesner P, Hjortdal J. Toric intraocular lenses in the correction of astigmatism during cataract surgery: a systematic review and meta-analysis. Ophthalmology. 2016;123:275-86.

25. Jivrajka R, Shammas MC, Boenzi T, Swearingen M, Shammas HJ. Variability of axial length, anterior chamber depth, and lens thickness in the cataractous eye. J Cataract Refract Surg. 2008:34:289-94.

26. Olsen T, Arnarsson A, Sasaki H, Sasaki K, Jonasson F. On the ocular refractive components: the Reykjavik eye study. Acta Ophthalmol Scand. 2007:85:361-6.

27. Nemeth G, Szalai E, Berta A, Modis L Jr. Astigmatism prevalence and biometric analysis in normal population. Eur J Ophthalmol. 2013;23:779-83.

28. Mohammadi M, Naderan M, Pahlevani R, Jahanrad A. Prevalence of corneal astigmatism before cataract surgery. Int Ophthalmol. 2016;36:807-17.

29. Read SA, Collins MJ, Carney LG. A review of astigmatism and its possible genesis. Clin Exp Optom. 2007;90:5-19.

\section{Submit your next manuscript to BioMed Central and we will help you at every step:}

- We accept pre-submission inquiries

- Our selector tool helps you to find the most relevant journal

- We provide round the clock customer support

- Convenient online submission

- Thorough peer review

- Inclusion in PubMed and all major indexing services

- Maximum visibility for your research

Submit your manuscript at www.biomedcentral.com/submit

) Biomed Central 